\title{
THE AMINO TERMINAL SEQUENCE OF SEVERAL TOXINS FROM THE VENOM OF THE MEXICAN SCORPION CENTRUROIDES NOXIUS HOFFMANN
}

\author{
by \\ LOURIVAL DOMINGOS POSSANI*, MYRNA A. R. DENT \\ Universidad Nacional Autónoma de Mexico \\ Instituto de Investigaciones Biomédicas, \\ Apartado Postal 70-247 México 20 D. F., Mexico, and \\ Max-Planck-Institut für Ernährungsphysiologie, \\ Rheinlanddamm 201, D-4600 Dortmund* \\ and \\ BRIAN M. MARTIN, ALFRED MAELICKE \\ Max-Planck-Institut für Ernährungsphysiologie \\ Rheinlanddamm 201, D-4600 Dortmund, West Germany \\ and \\ IB SVENDSEN \\ Department of Chemistry, Carlsberg Laboratory, \\ Gamle Carlsberg Vej 10, DK-2500 Copenhagen, Valby
}

Keywords: Scorpion toxins, Centruroides noxius, amino acid analysis, amino acid sequence, sequence homology

The soluble venom from the Mexican scorpion Centruroides noxius HofFMANN was fractionated by Sephadex G-50 chromatography followed by ion exchange separation on carboxymethylcellulose and Bio-Rex 70 columns. Six homogeneous toxins were obtained by this procedure. The amino acid composition and the amino-terminal amino acid sequence was determined for four of them. They are all basic polypeptides with a molecular weight in the order of 7,000, containing from 59 to 65 amino acid residues with four disulphide bridges.

Toxin II.9.2.2 has the N-terminal sequence: Lys-Glu-Gly-Tyr-Leu-Val-Asp-Lys-Asn-Thr-Gly-Cys-Lys-TyrGlu-Cys-Leu-Lys-Leu-Gly-Asp-Asn-Asp-Tyr-Cys-Leu-Arg-Glu-Cys-Lys-Gln-Gln-Gly-Tyr-Lys-Gly-Ala-GlyGly-Tyr-Cys-Tyr-Ala-Phe-Ala-Cys-Trp-Cys.

The N-terminal sequence of toxin II-10 was shown to be: Lys-Glu-Gly-Tyr-Leu-Val-Asn.

For Toxin II- 13 the amino acid N-terminal sequence is: Lys-Glu-Gly-Tyr-Ile-Val-Asp-Tyr-His-Asp-Gly-CysLys-Tyr-X-Cys-Tyr-Lys-Leu-Gly-Asp-Asn-Asp-Tyr, and Toxin II-14 has the amino terminal sequence: LysAsp-Gly-Tyr-Leu-Val-Asp-Ala-Lys-Gly-Cys-Lys-Lys-Asn-Cys-Tyr-Lys-Leu-Gly-Lys-Asn-Asp-Tyr-Cys-AsnArg-Glu-Cys-Arg-Met-Lys-His-Arg-Gly. Some of the biological properties of these toxins are discussed in the communication.

*As visiting professor of the Alexander von Humboldt Foundation. 


\section{INTRODUCTION}

The scorpions from the genus Centruroides are widely distributed in Mexico and at least six species are very poisonous to mammals (4). Only the toxins from two species have been studied in detail, Centruroides sculpturatus EwING (1) and Centruroides suffusus suffusus (13). We have recently described two toxins from Centruroides elegans ThORELL (10), one toxin from Centrurorides limpidus tecomanus HofFmanN (8) and several toxins from the venom of Centruroides noxius Hoffman (2). No information on the primary structure of the toxins from Centruroides noxius is as yet available. In this communication we report the amino terminal sequence of four different toxins obtained from the venom of Centruroides noxius. Part of this work was presented as an abstract during the 4th European Symposium on Plant, Animal and Microbial Toxins (6).

\section{MATERIALS AND METHODS}

\subsection{Materials}

Scorpions collected in the state of Nayarit (Mexico), were anaesthetized with carbon dioxide and the venom was obtained by electrical stimulation of the telsons. The venom was recovered in double distilled water, centrifuged for 10 minutes in a Sorvall centrifuge equipped with an SS-34 rotor and operated at 10,000 rpm. The supernatant was pooled, lyophilized and stored until used at $-20^{\circ} \mathrm{C}$.

Sephadex G-50, medium and fine, was obtained from Pharmacia Fine Chemicals, Uppsala, Sweden. CM-cellulose (CM-32) was a product of Whatman Inc., Clifton, N. J., USA. Iodo $\left[2-{ }^{4} \mathrm{C}\right]$ acetic acid $(50 \mu \mathrm{Ci})$ was obtained from Amersham Buchler, Braunschweig, West Germany and diluted to the appropriate specific activity with cold iodoacetic acid.

The chemicals used for sequence determination were described previously (9). All other chemicals were reagent grade.

\subsection{Lethality tests}

The lethality of the different toxic components obtained during the isolation procedure was evaluated always in 18-20 g albino mice (strain NMRI) by intraperitoneal injection as described in detail in the accompanying paper (9). The same designations 'Lethal', 'Toxic' and 'Nontoxic' were used (see footnote of Table I).

\subsection{Purification of toxins}

Three grams of lyophilized soluble venom was dissolved ( $80 \mathrm{mg}^{-\mathrm{ml}^{-1}}$ ) in $0.02 \mathrm{M}$-ammonium acetate buffer, $\mathrm{pH} 4.7$ and fractionated based on molecular weight difference. Six independent applications of approximately $500 \mathrm{mg}$ each of soluble venom were gel filtered on a Sephadex G-50 column. Figure 1 presents an example of the chromatogram obtained. Fraction II contained about $63 \%$ of the material applied to the column (by absorbancy at $280 \mathrm{~nm}$ ) and was the only toxic fraction. Further separation of fraction II on CM-cellulose ion exchange columns gave essentially the same results as previously described (11). At least fourteen different components were developed by a linear $\mathrm{NaCl}$ gradient $(0$ to $0.5 \mathrm{M})$ in $0.02 \mathrm{M}$-ammonium acetate buffer, pH 4.7 (Fig. 2). Recoveries and lethality tests of the different components are shown in Table I. When necessary, further rechromatography was conducted using the same conditions, or using a Bio-Rex 70 Column as already published (11). The latter procedure was particularly important for the final purification of toxin II.9.2.2 (see section 3). Detailed data are presented in the footnotes of the figures and in the preceding publication (11).

Homogeneity of the different toxins was verified by polyacrylamide gel electrophoresis in the acetate-urea- $\beta$-alanine system of REISFELD et al. (12), and by amino acid sequencing.

\subsection{Reduction and carboxymethylation}

Reduction of the toxins was done as described previously (9). However, instead of 4-vinylpyri-

\footnotetext{
Abbreviations: $\mathrm{BSA}=$ bovine serum albumin; $\mathrm{C}=$ Centruroides; $\mathrm{CM}=$ carboxymethyl; $\mathrm{HPLC}=$ high performance liquid chromatography; N.n.s. $=\alpha$-toxin from Naja naja siamensis; PTH $=$ phenylthiohydantoin; $\mathrm{RCM}=$ reduced carboxymethylated; TLC $=$ thin layer chromatography.
} 


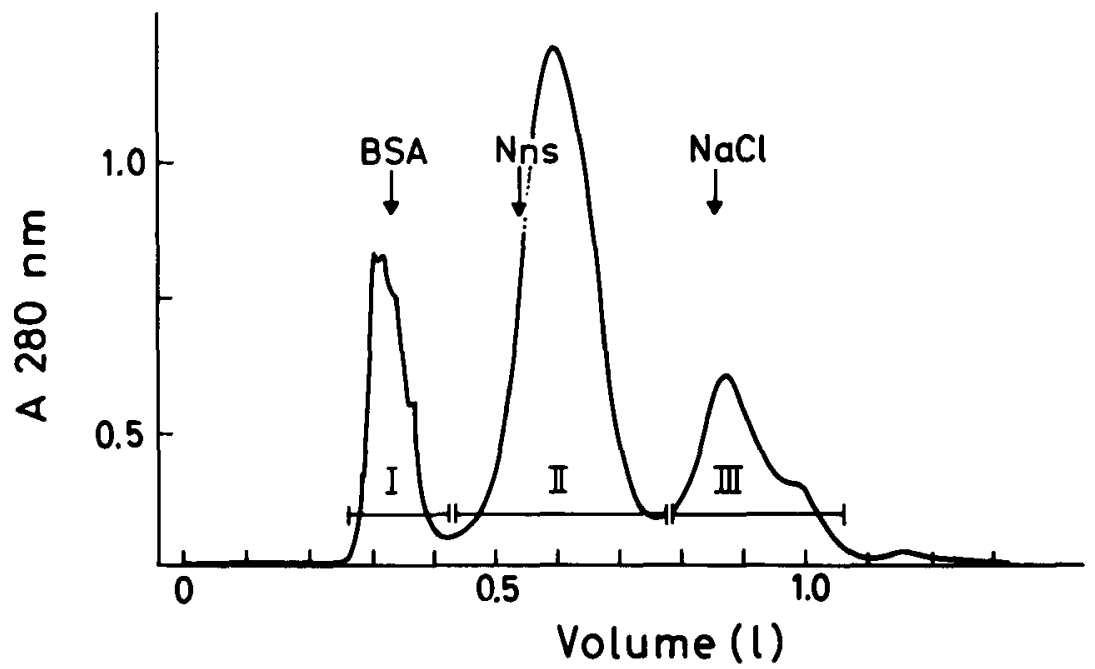

Figure 1. Fractionation of the soluble venom.

A $2.9 \times 170 \mathrm{~cm}$ column of Sephadex G-50, medium, equilibrated with 0.02 M-ammonium acetate, $\mathrm{pH} 4.7$ was loaded with $6.3 \mathrm{ml}$ of soluble venom containing 500 absorbance units at $280 \mathrm{~nm}$ and eluted with the same buffer at a flow rate of $50 \mathrm{ml} \cdot \mathrm{h}^{-1}$. Fractions of $10 \mathrm{ml}$ were collected and pooled as indicated by the horizontal bars. Fractions I, II and III contain approximately 17\%,63\% and $20 \%$ respectively of the material recovered. The only toxic fraction (n.II) was usually lyophilized and kept at $-20^{\circ} \mathrm{C}$ prior to further chromatography. BSA (bovine serum albumin, molecular weight 66,200 ), N.n.s. ( $\alpha$-toxin from Naja naja siamensis, molecular weight 8,000 ), and $\mathrm{NaCl}$ were run separately as molecular weight markers.

dine, iodo $\left[2-{ }^{14}\right.$ Clacetic acid was used for alkylation. The reduced carboxymethylated toxin was recovered free of excess reagents after chromatography (Figure 3) on Sephadex G-50 $(2.5 \times 120 \mathrm{~cm})$. The radioactivity incorporated was approximately equal for all toxin species.

\subsection{Sequence and amino acid analysis}

Automated EDMAN degradation' was done using the Beckman $890 \mathrm{C}$ Sequencer according to the method of EDMAN and BEGG (3). Methodology for the Sequencer has been described in detail in the preceding paper (9) and elsewhere



Figure 2. Ion exchange chromatography of fraction II from Sephadex G-50.

A CM-32 column $(0.9 \times 27 \mathrm{~cm})$ equilibrated with $0.02 \mathrm{M}$-ammonium acetate, $\mathrm{pH} 4.7$ was loaded with $95 \mathrm{mg}$ (dry weight) or 116.6 absorbancy units (at $280 \mathrm{~nm}$ ) of fraction $\mathrm{II}(17 \mathrm{ml})$ indicated by the letter $\mathrm{L}$. A linear gradient containing $240 \mathrm{ml}$ each of equilibration buffer and this buffer containing $0.5 \mathrm{M}-\mathrm{NaCl}$ was started as indicated by $\mathrm{G}$. At the end of the gradient the column was washed with the same buffer containing $1 \mathrm{M}-\mathrm{NaCl}$ shown by W. The flow rate was $30 \mathrm{ml} . \mathrm{h}^{-1}$ and fractions of $2.4 \mathrm{ml}$ each were collected and pooled as indicated by the horizontal bars. Recoveries and lethality tests are shown in Table I. 
Table I

Recovery and lethality of components obtained from the CM-cellulose column (Fig. 2).

\begin{tabular}{|c|c|c|c|}
\hline Protein component & Amount recovered ${ }^{a)}$ & $\%$ Recovery & Lethalityb) \\
\hline $\begin{array}{l}\text { Fraction II applied } \\
\left(\mathrm{A}_{280}^{\mathrm{Icm}}=116.6 \text { units }\right) \\
\text { Fractions obtained }\end{array}$ & 116.0 & 99.9 & lethal \\
\hline II - 1 & 1.0 & 0.9 & not tested \\
\hline II -2 & 6.5 & 5.6 & non toxic \\
\hline II - 3 & 0.6 & 0.5 & non toxic \\
\hline II - 4 & 7.7 & 6.6 & non toxic \\
\hline II -5 & 8.6 & 7.4 & non toxic \\
\hline II - 6 & 20.1 & 17.3 & toxic \\
\hline II - 7 & 12.6 & 10.9 & non toxic \\
\hline Il - 8 & 14.1 & 12.1 & lethal \\
\hline II - 9 & 21.4 & 18.4 & lethal \\
\hline II - 10 & 8.5 & 7.3 & lethal \\
\hline II - 11 & 3.6 & 3.1 & lethal \\
\hline II -12 & 3.8 & 3.3 & toxic \\
\hline II - 13 & 2.4 & 2.0 & lethal \\
\hline II -14 & 5.1 & 4.4 & toxic \\
\hline
\end{tabular}

a) The values represent total absorbancy units at $280 \mathrm{~nm}$.

b) Protein was injected intraperitoneally into $20 \mathrm{~g}$ mice. When small amounts of toxin required a qualitative assay then 20-40 $\mathrm{g}$ of protein (by absorbancy at $280 \mathrm{~nm}$ assuming that $A_{280}^{\mathrm{Icm}} \mathrm{nm}=1 \mathrm{mg} \cdot \mathrm{ml}^{-1}$ ) was injected into one or two mice. The term 'lethal' means that the component at the dose injected was enough to kill the tested mouse within $20 \mathrm{~h}$ of injection; 'Toxic' means that the mouse shows any of the following symptoms: excitability, salivation, temporary paralysis of rear limbs, dyspnea, but recovered within $20 \mathrm{~h}$ after injection; 'Non-toxic' means normal behaviour similar to injection of $0.9 \% \mathrm{NaCl}$.

(14). Identification of the resulting PTH-amino acids was made by HPLC using a HewlettPackard chromatograph Model 1084B (14) and

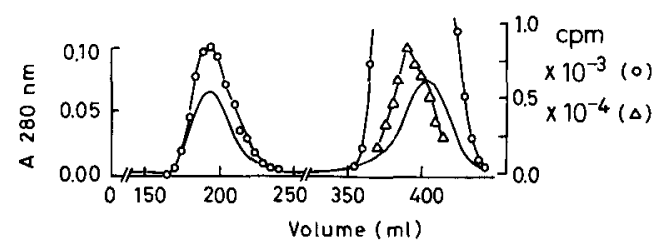

Figure 3. Sephadex G-50 gel filtration of RCM-toxin II-14.

One $\mathrm{mg}$ of the toxin reduced with iodo $\left[2-{ }^{14} \mathrm{C}\right.$ acetate was loaded on Sephadex G-50, fine column $(2.5 \times 120 \mathrm{~cm})$ equilibrated and eluted with $20 \%$ acetic acid. The flow rate was $30 \mathrm{ml}^{-1} \mathrm{~h}^{-1}$ and fractions of $5 \mathrm{ml}$ were collected. The fractions eluting between 170 and $230 \mathrm{ml}$ were pooled and lyophilized prior to analysis and sequencing. The recovery was quantitative. Absorbancy at $280 \mathrm{~nm}$ and radioactivity measurements are indicated. in some cases by TLC (5). ${ }^{14} \mathrm{CM}$-cysteine was located by both HPLC and scintillation counting on a Packard 3003 Liquid Scintillation counter.

Amino acid analysis were performed on a Durrum D-500 after hydrolysis in $5.7 \mathrm{~N}-\mathrm{HCl}$ at $110^{\circ} \mathrm{C}$ in vacuo as described (9).

\section{RESULTS AND DISCUSSION}

At least 40,000 scorpions were "milked" during the past three years in order to collect a few grams of dry venom. The mean lethal dosis $\left(\mathrm{LD}_{50}\right.$ ) for the soluble venom is $0.26 \mu \mathrm{g} \cdot \mathrm{g}^{-1}$ weight of albino mice (2). The water extracted venom (soluble venom) was chromatographed. The first separation in Sephadex G-50 column afforded three distinct fractions (Fig. 1), from which fraction I contained higher molecular weight components (hyaluronidase among them) and fraction III contained small molecular weight peptides and other free aminated derivatives (M.A.R. Dent and L. D. Possani, unpub- 
lished observations). Fraction II corresponding to molecular weight components of approx. 3,000 to 15,000 contained the toxic polypeptides that were further purified by ion exchange chromatography as indicated in section 2.3. The total amount of fraction II varied from $63 \%$ (this communication) to $71 \%$ (11) depending on the chromatographic characteristics of the Sephadex column, but always constitutes the major portion of the soluble venom.

The general profile of the chromatograms after CM-cellulose was reproducible (Fig. 2 in this communication and in reference $i i)$. This initial ion exchange step allowed in all cases, the separation of at least 14 different constituents. Sometimes, however, the position of the less basic components (II-1 to II-5, Fig. 2) can be different, depending on the characteristics of the column (size), volume of the gradient or amount of protein applied, even when the buffer and $\mathrm{NaCl}$ gradients are identical. The most constant part of the chromatogram is the region where the basic fractions $11-8$ to $11-i 4$ are found (Fig. 2 and reference 11 ). Ten independent chromatograms gave the same results. If the content of the toxic fractions from Table I are added up, they account for $77 \%$ of the total material chromatographed on the CM-cellulose coiumn. From this figure, and the recovery obtained in the Sephadex G-50 column $(63-71 \%)$ it can be concluded that in the order of $48 \%$ to $55 \%$ of the total soluble venom is represented by some kind of toxic protein. The toxicity of fraction II-6 (Fig. 2) to mammals (mouse) is very low, but this fraction is a potent reversible paralysing agent for crustaceans e.g. $\mathrm{crab}$ and crayfish. Fraction II-5 appears to be an even more potent toxin in the crustaceans studied (L. D. Possani and J. MochCa-Morales, unpublished observations). Fraction II-8 is a lethal component to mice at the doses assayed, but unfortunately is still heterogeneous in the polyacrylamide gel electrophoresis system (12) tested. The next fraction, II-9, was further chromatographed, first in the same conditions as Fig. 2 and after using Bio-Rex-70 as already described (11). and gave rise to the homogeneous toxin II.9.2.2. This polypeptide is lethal to mice. Preliminary experiments have shown that a radiolabelled I'25-toxin II.9.2.2 derivative is capable of binding to membranes obtained from synaptosomes of the central nervous system of mouse (L. D. Possani and J. MochCa-Morales, unpublished).

If only 2-4 tubes (peak fractions) from the remaining toxic components (II-10 to II-14) from figure 2 are analysed in acetate-urea- $\beta$ alanine polyacrylamide gel electrophoresis (12) they show sufficient homogeneity (only one band with 50-100 $\mu$ grotein applied to the gel) to be used for chemical analysis and tested for biological properties.

The 2 peak tubes from fraction II-10 are extremely toxic to mammals and have been recently shown by Carbone, Wanke, Prestepino, Maelicke and Possani (unpublished) to be a reversible blocker of the $\mathrm{Na}^{+}$channel in the squid giant axon, under voltage clamp dependent experiments. Fractions II-11 to II- 14 all are toxic to mammais but physiological experiments have not been completed, yet. As it can be observed again in Fig. 2 and Table I, the major toxins obtained in pure form, so far, are toxin II 9.2.2. II-10 (peak tubes) to II-14 (peak tubes). Toxin II- 11 to II-13 (peak-tubes) were obtained only in small amounts. Since the biological effects of these toxins seemed to be different, it was very tempting to see the variations in their amino acid compositions and sequences. The toxins were reduced and carboxymethylated with iodo $\left[2-{ }^{4} \mathrm{C}\right]$ acetic acid. Both amino acid analysis and automatic EDMAN degradation were made on the reduced carboxymethylated toxins (Figure 3). As it can be observed in Table II. the molecular weight estimated for the four toxins studied is in the range of 7.000 , having 59 amino acid residues plus possible tryptophans for the smallest toxin II-14 to 65 residues including tryptophan, for the largest toxin II.9.2.2. The values of half cystines were found to be consistently low for toxins II-10, II-13 and II-14. The chromatograms from the amino acid analyzer have always shown trace amounts of unalkylated cystines. For this reason in Table II we have admitted possible variations of halfcystine between $6-8$. However, based on homologies of other North American scorpion toxins (1, 13), with the venom of Centruroides species we assume that a value of 8 half-cystines is the more plausible one. Another interesting finding is the presence of methionine in the amino acid composition of toxin II-14. This amino acid residue is nonexistent in practically all the toxins 
L. D. Possanı et al.: C. noxius toxin sequences

Table II

Amino acid compositions of toxins from Centruroides noxius HofrmanN.

\begin{tabular}{|c|c|c|c|c|}
\hline Amino acid & Toxin II-9.2.2 & Toxin II-10 & Toxin II-13 & Toxin II-14 \\
\hline Asp & 6 & $6(5.8)^{b)}$ & $6(5.6)^{b)}$ & $7(7.0)^{\mathrm{b})}$ \\
\hline $\mathrm{Thr}^{\mathrm{c})}$ & 2 & $4(3.5)$ & $2(1.8)$ & $3(2.7)$ \\
\hline $\left.\operatorname{Ser}^{c}\right)$ & 1 & $3(2.6)$ & $2(2.1)$ & $4(3.6)$ \\
\hline Glu & 7 & $6(5.5)$ & $4(4.1)$ & $2(2.3)$ \\
\hline Pro & 2 & $2(2.0)$ & $2(2.2)$ & $2(2.3)$ \\
\hline Gly & 7 & $7(7.0)$ & $8(8.0)$ & $8(8.0)$ \\
\hline Ala & 4 & $3(2.8)$ & $4(3.6)$ & $1(1.2)$ \\
\hline $\mathrm{Val}^{\mathrm{d})}$ & 2 & $1(1.4)$ & $2(1.9)$ & $1(0.8)$ \\
\hline Met & 0 & $0(0.0)$ & $0(0.0)$ & $1(0.8)$ \\
\hline Iled) & 1 & $1(0.9)$ & $1(1.1)$ & $0(0.0)$ \\
\hline Leu & 6 & $4(4.0)$ & $4(4.3)$ & $4(3.7)$ \\
\hline Tyr & 6 & $5(5.3)$ & $6(6.4)$ & $6(5.8)$ \\
\hline Phe & 1 & $2(1.9)$ & $1(1.2)$ & $1(1.2)$ \\
\hline His & 1 & $1(0.7)$ & $1(1.4)$ & $1(1.0)$ \\
\hline Lys & 8 & $7(6.7)$ & $7(6.8)$ & $7(7.2)$ \\
\hline Arg & 2 & $2(2.2)$ & $2(2.1)$ & $3(2.6)$ \\
\hline $\mathrm{CM}-\mathrm{Cys} \mathrm{s}^{\mathrm{e})}$ & 8 & $8(5.4)$ & $8(6.1)$ & $8(5.8)$ \\
\hline $\operatorname{Trp}$ & 1 & n. d. & n. d. & n. d. \\
\hline Total & 65 & $62+\operatorname{Trp}$ & $60+\operatorname{Trp}$ & $59+\operatorname{Trp}$ \\
\hline
\end{tabular}

a) Values taken from reference 11 .

b) Values between parenthesis are residue/mole based on glycine $=7,8$ and 8 respectively for toxin II-10, II-13 and II-14.

c) Values obtained from extrapolation to 0 time of hydrolysis.

d) Values obtained after $48 \mathrm{~h}$

e) Half-cystines determined as carboxymethyl-cysteine after reduction and alkylation (see section Results and Discussion).

f) n. d. = not determined.

I -9.2 .2$

II -14

II -13

II -10

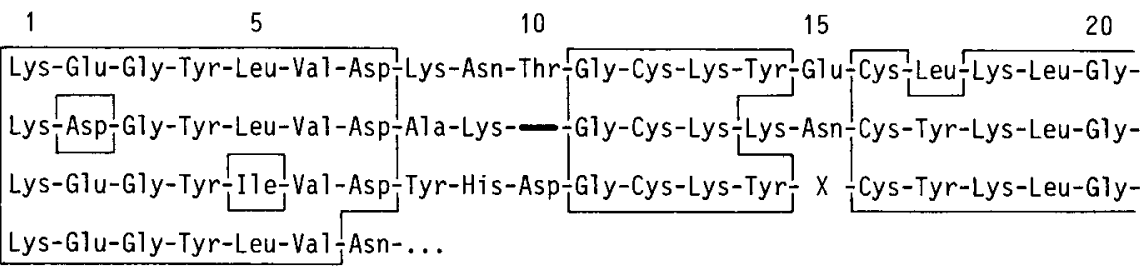

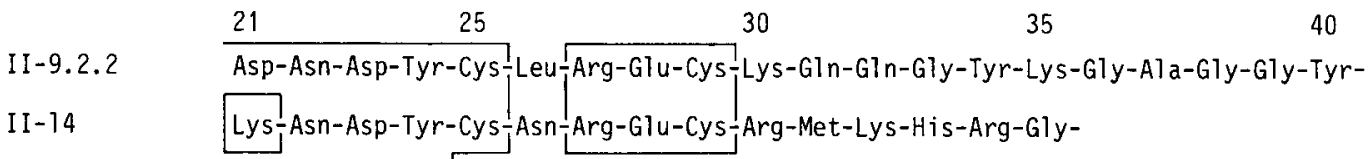

II-13 Asp-Asn-Asp-Tyr - ...

$\begin{array}{ll} & 41 \\ \text { II-9.2.2 } & \text { Cys-Tyr-Ala-Phe-Ala-Cys-Trp-Cys-... }\end{array}$

Figure 4. Comparison of the amino terminal amino acid sequences of toxins II.9.2.2, II-10, II-13 and II-14 from the venom of the scorpion Centruroides noxius.

Half-cystines have been aligned in all four sequences and gaps are introduced to maximize homology. The numbering system for amino acid positions has been adapted accordingly. Residues which are invariant in the toxins are enclosed in boxes. $\mathrm{x}$ indicates an unidentified residue. 
purified from Centruroides species $(1,2,8,13)$, so far. From the North African scorpion toxins it seems also to be a general rule, i.e., the lack of methionine (13). Exceptions to this rule are the toxins $\gamma$, III- 10 and III- 8 from Tityus serrulatus from Brazil $(7,9)$.

It is clear from Table II that these four toxins have different amino acid compositions and these differences are even more evident in the amino terminal sequence.

The RCM-toxin II-9.2.2 was sequenced, using 50 nmoles, allowing the identification of the first 48 amino acids. The repetitive yield for this run was $96 \%$. The sequence of amino acids obtained is presented and compared with those from II- 10 , II-I3 and II-I4 in Figure 4 . It is worthwhile observing that the sequence $\mathrm{Cys}_{46} \operatorname{Trp}_{47} \mathrm{Cys}_{48}$ was already predicted by our preliminary spectroscopic characterization of toxin II.9.2.2 (1 I). Some problems were encountered when RCM-toxin II-10 (20 nmoles) was submitted to automatic EDMAN degradation. The repetitive yield was $96 \%$ up to residue 6 , with a drastic decrease in yield with the Asn 7 , possibly due to imide formation. Reduced alkylated toxin II-13, 24 nmoles, was sequenced 24 steps with 23 amino acids identified. The repetitive yield was approximately $96 \%$ up to step 20 . RCMtoxin II-14, 22 nmoles, was sequenced for 34 cycles with positive identification of all residues. The repetitive yield for this analysis was $95 \%$. The presence of Met 30 is unusual for scorpion toxins as discussed previously. At the same time, the position of this residue in the middle of the molecule makes the completion of the amino acid sequence a much more attractive project.

When we analyse Figure 4 for areas of homologous sequence it is clear that these four toxins have extensive areas with identical amino acid sequences. There are four stretches of sequence with high homology in the first half of the molecule. Residues 1 to 7 have practically the same sequence $\mathrm{Lys}_{3} \mathrm{Glu}_{2} \mathrm{Gly}_{3} \mathrm{Tyr}_{4} \mathrm{Leu}_{5} \mathrm{Val}_{6} \mathrm{Asp}_{7}$ in all four toxins studied, except for two conservative replacements at $\mathrm{Asp}_{2}$ and Iles for toxin II- 14 and II- 13 respectively.

The second identical sequence appears at Gly $_{11} \mathrm{Cys}_{12} \mathrm{Lys}_{13}$ for three toxins and $\mathrm{Tyr}_{14}$ for toxins II.9.2.2 and II-10. The amino acid residues $\mathrm{Cys}_{16}$ to $\mathrm{Cys}_{25}$ are located in the third highly conservative region in these sequences, except for 2 places $\mathrm{Leu}_{17}$ in toxin II.9.2.2 and Lys $_{21}$ in toxin II-14. The latter toxins have a fourth common area at $\operatorname{Arg}_{27} \mathrm{Glu}_{28}$ and $\mathrm{Cys}_{29}$. The positions 8 to $10,15,26$ and 30 to 35 are extremely variable regions in these sequences. If we compare the degree of homologies found in the scorpion toxins of Centruroides noxius with that of Tityus serrulatus (9) it is evident that the Centruroides toxins seem to be more homologous among themselves than the Tityus toxins when similarly compared.

However, further comparative studies or attempts to correlate these structural differences with the different biological functions or mechanisms of action of these toxins, have to await more sequence data, especially for toxin II-10 and to some extent for toxin II-13.

\section{ACKNOWLEDGEMENTS}

The excellent technical assistance of Mrs. Lone Sørensen and Bodil Corneliussen is gratefully acknowledged. The authors wish to express their appreciation to Professor $M$. OTTESEN of Carlsberg for allowing us the use of the Sequencer facilities. The zoological classification of the scorpions used in this work was kindly done by Professor J. JuLiá (Instituto Nacional de Higiene-México) to which the authors are indebted. The help of the students J. Mochca-Morales, G. Ramírez, F. Coronas and M. VARELA during the smilking" of the scorpions are deeply acknowledged.

This work was partially supported by Grant PCCBNAL 811370 from the Consejo Nacional de Ciencia Y Tecnologia (México).

\section{REFERENCES}

1. Babin, D. R., D. D. WatT, S. M. Goos \& R. V. MLEJNEK: Amino acid sequences of neurotoxic protein variants from the venom of Centruroides sculpturatus Ewing. Arch. Biochem. Biophys. 164, 694-706 (1974)

2. Dent, M. A. R., L. D. Possani, G. A. Ramirez \& P. L. Fletcher, Jr.: Purification and characterization of two mammalian toxins from the venom of the Mexican scorpion Centruroides noxius Hoffmann. Toxicon 18, 343-350 (1980)

3. EDMAN, P. \& G. BeGG: A protein sequenator. Eur. J. Biochem. 1, 80-91 (1967) 
4. Hoffmann, C.: Nuevas consideraciones acerca de los alacranes de México. An. Inst. Biol., 9, 317337 (1938)

5. Kulbe, K. D.: Micropolyamide thin-layer chromatography of phenylthiohydantoin amino acids (PTH) at the subnanomolar level. A rapid microtechnique for simultaneous multisample identification after automated Edman degradations. Anal. Biochem. 59, 564-573 (1974)

6. Martin, B., L. D. Possani, M. A. R. Dent \& A. MaELICKE: N-terminal sequence of Toxin II.9.2.2 from the venom of the scorpion Centruroides noxius. Abstract to the 4th European Symposium on Animal, Plant and Microbial Toxins, Marseille, France, 24-27 June, 1981

7. Possani, L. D., A. C. Alagon, P. L. Fletcher, Jr. \& B. W. ERICKson: Purification and properties of mammalian toxins from the venom of the Brazilian scorpion Tityus serrulatus Lutz and Mello. Arch. Biochem. Biophys. 180, 394-403 (1977)

8. Possani, L. D., P. L. Fletcher, Jr., A. B. C. Alagon, A. C. Alagon \& J. Z. Julia: Purification and characterization of a mammalian toxin from venom of the Mexican scorpion Centruroides limpidus tecomanus Hoffman. Toxicon 18, 175-183 (1980)
9. Possani, L. D., B. M. Martin, J. MochcaMorales \& I. Svendsen: Purification and chemical characterization of the major toxins from the venom of the Brazilian scorpion Tityus serrulatus Lutz and Mello. Carlsberg Res. Commun. 46, 195-205 (1981)

10. Possani, L. D., G. A. Ramirez, P. L. Fletcher, Jr. \& M. A. H. Gurrola: Isolation of two mammalian toxins from the venom of the Mexican scorpion Centruroides elegans Thorell. FEBS Lett. 91, 261-264 (1978)

11. Possani, L. D., W. E. Steinmetz, M. A. R. Dent, A. C. Alagon \& K. Wüthrich: Preliminary spectroscopic characterization of six toxins from Latin American scorpions. Biochim. Biophys. Acta 669, 183-192 (1981)

12. Reisfeld, R. A., U. J. Lewis \& D. E. Williams: Disk electrophoresis of basic proteins and peptides on polyacrylamide gels. Nature 281283 (1962)

13. Rochat, H., P. Bernard \& F. Couraud: Scorpion toxins: Chemistry and mode of action. Adv. Cytopharm. 3, 325-334 (1979)

14. Svendsen, I., B. Martin \& I. Jonassen: Characteristics of hiproly barley III. Amino acid sequences of two lysine-rich proteins. Carlsberg Res. Commun. 45, 79-85 (1980) 